\title{
14 Writing Our Language
}

\section{Sheena Shah and Matthias Brenzinger}

\section{Introduction}

Language communities and individual speakers of oral languages often express interest in the development of community orthographies, i.e. writing conventions for their ancestral languages. In this chapter, we review practical and ideological considerations in the writing of oral languages by asking some questions: 'Who will write / read?', 'What will be written?', 'How will oral languages be reduced to writing?' In our discussion, we focus on languages which have not been written before and where orthographies have been introduced only recently.

\section{Purposes and Uses of Writing}

Speakers of minority languages often accept discriminatory judgments from others about them and their languages, e.g. that their mother tongues are merely utterances without grammatical rules, which therefore cannot be written. The following example from the Khwe community in Namibia demonstrates the importance of writing in challenging these negative stereotypes. When community members wrote their language for the first time at a community workshop on the $15^{\text {th }}$ of September 1996, Khwe became a written language. In a collaborative effort between Khwe speakers and linguists, an alphabet and other writing conventions were developed for their oral language. When writing his first Khwe words, David Soza Naudé, one of the workshop participants, who later became the key person in running community literacy workshops, stated with surprise and astonishment, 'So we actually speak a real language'.

While reading and writing do not commonly play important roles in the daily life activities among the Khwe and other marginalized rural communities, establishing a community orthography might have an immense impact for them on a symbolic level. Although equating 'real language' with 'written language' reflects the widespread discriminatory judgments mentioned above, writing their language can boost their self-esteem and 
enhance their confidence and respect for their own language and culture (for more on attitudes and ideologies, see Chapter 8). For example, the Sandawe in Tanzania felt that their worth as a group increased after a Sandawe orthography was developed. Elisabeth Hunziker of SIL International recalls that for many years, 'they had gotten used to being looked down upon by other ethnic groups of the country as being the ones whose language was impossible to pronounce, let alone write. Now with the alphabet, this was no longer the case'. Community members often desire written materials in their languages, which, once developed, are cherished and treasured. Books, booklets or even just small pamphlets are shared among community members and shown with pride to outsiders.

The practical use of community orthographies often begins with the production of sign boards with local place names that testify the ancestry of the land. These sign boards on the one hand may support communitybased tourism, but on the other hand can also constitute arguments for claims for ancestral lands.

The publication of religious texts, such as hymns, prayers and the Bible, in as many languages as possible was for a long time at the core of Christian mission work in Africa, Latin America and Asia. With this aim in mind, missionaries wrote grammars and dictionaries of local languages. Many speakers of marginalized languages became literate by reading Christian texts, which still make up the bulk of publications in languages of many smaller-sized communities.

Another level in writing community languages is reached when they are used to take memos and to make notes at community meetings, to record decisions and detail agreements, etc. This is, for example, practised by the Jul'hoan community in Namibia. The advantage of using their own language in these official contexts is that the non-literate speakers, who often constitute the majority in many such communities, can also participate in and contribute to discussions concerning community affairs because the notes can be read back to them.

Writing oral languages can also serve as a means to document the community's intellectual heritage, namely oral traditions relating to their history, rituals, environmental management, traditional economies, healing and spiritual well-being, etc. (see Figure 14.1). A critical take on reading and writing in hitherto oral languages emphasizes the importance of oral practices in many traditional societies. While oral traditions can be recorded in audio and video sessions and stored electronically, due to lack of basic infrastructure (access to electricity, Internet, etc.) in most rural areas, written documents are much easier to manage and access.

Writing a language is essential for mother tongue-based multilingual education, and also for immersion education for language revitalization 


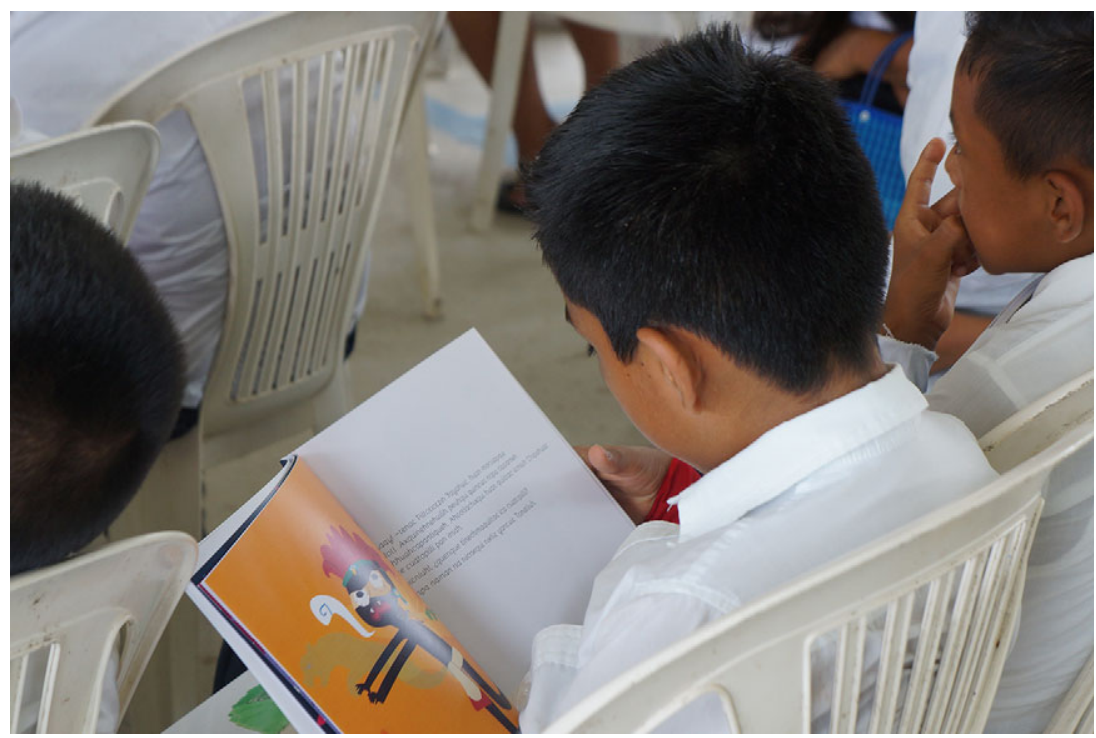

Figure 14.1 A Nahua boy reading an ancient creation story written in his variant. Chicontepec, Mexico. Photo by Justyna Olko

(see Chapter 15). This is particularly important, because literacy rates among speakers of threatened languages are often low and illiteracy is one of the crucial indicators to identify discrimination and marginalization. Children from such marginalized communities regularly perform poorly when their own languages are not used in the educational system. ${ }^{1}$ Countless studies have demonstrated that children learn best in and through their mother tongues; despite this common knowledge, millions of children around the world are educated in languages other than their own. The plea for mother tongue-based multilingual education is an important argument for supporting the writing of oral languages. Government institutions, NGOs, as well as linguists may play supporting roles in communities' attempts towards developing writing conventions, producing teaching and learning materials, fostering the use of the language and establishing language rights.

Finally, writing can play a crucial role in the survival of threatened languages. Where ancestral languages are no longer spoken in the family,

${ }^{1}$ See e.g. UNESCO, Improving the Quality of Mother Tongue-Based Literacy and Learning: Case Studies from Asia, Africa and South America (Bangkok: UNESCO Bangkok, 2008), https:// unesdoc.unesco.org/ark:/48223/pf0000177738. 
children no longer acquire them naturally in their home environment. For this reason, ancestral languages are increasingly transmitted through formal and informal teaching. The design and production of teaching and learning materials for community languages are often considered central by language revival and revitalization movements. In these cases, the development and establishment of community orthographies are prerequisites, since these materials are mainly written, for example in booklets, readers, textbooks and dictionaries. When we work with last speakers of languages, learners don't speak the languages fluently and often acquire new words through reading them. For this purpose, learning can be made easier if orthographies represent the speech sounds as closely as possible.

\section{Designing Community Orthographies}

Many linguists treat orthography development as a technical issue in which they identify the phoneme inventory and then aim at representing one distinctive speech sound with one character or symbol. Hangul, the alphabetic system used in writing Korean, represents the distinctive speech sounds of that language perfectly: words can be correctly pronounced simply by reading them, even by non-speakers. Most orthographies, however, especially those with long traditions, do not follow this principle. For example, the idiosyncratic nature of spelling is an obstacle in learning and writing English. Irregular spellings and pronunciation in English are the topic of many poems, including, for example, the classic English poem 'The Chaos', written by the Dutch traveller Gerard Nolst Trenité in 1920. It contains about 800 of the worst irregularities in English spelling and pronunciation, questioning for example why 'done' rhymes with 'fun' and not with 'gone'. English is one of those languages in which the written forms of spoken words must be learned in addition to the oral pronunciation. Learning to speak English from written texts alone is therefore not possible. In Korean, on the other hand, it is possible to do so after having learnt the Korean alphabet, which in itself takes only a few hours.

Socio-political contexts and cultural traditions are often determining factors in the choice of specific orthography conventions, or even of different writing systems. Socio-political conditions affect all levels, namely the writing systems, orthographies or even the use of specific characters or symbols representing speech sounds.

Speakers of threatened languages commonly speak or even write other languages, which are more dominant than theirs. The orthographies and writing systems established for dominant languages are crucial in choosing writing conventions for a threatened language, especially when these 
dominant languages are used in literacy campaigns and formal education. There are often heated debates within communities between proponents of different orthographies, e.g. those who want to make it easier to switch to and from majority languages vs. those who want to use orthography to stress distinctiveness.

Religious affiliation has triggered the use of different orthographies for one and the same language, for example, when missionaries of different denominations introduced distinct writing conventions for Tumbuka in Malawi. Dialectal variation may also lead to different orthographies. For example, the Western Aranda people in central Australia want to distinguish themselves from the neighbouring Eastern Arrernte people through the spelling used in their language. For them, their own orthography is a key symbol of their distinct identity.

National governmental policies may demand the use of specific writing conventions, so cross-border languages may develop parallel writing systems in different countries. This led, for example, to different writing systems for Afar, a Cushitic language, in the three countries in which it is spoken: Afar is written in the Ethiopian script in Ethiopia, in the Roman alphabet in Eritrea, and in the Arabic script in Djibouti. Another example of state regulations on writing conventions is the enforcement of the use of Roman letters for the representation of click consonants by the government of Botswana. The orthography of Naro was developed according to this directive, whereas the orthographies of all related languages, including the well-established orthography of Khoekhoegowab, use the click symbols from the International Phonetic Alphabet, which are easily acquired and used by community members, and which are used in all community orthographies of non-Bantu click languages in southern Africa (Figure 14.2).

In the past, when starting to write an oral language, it was often the case that a 'standard' language was imposed, which ignored the regional, socioeconomic, gender and generational variation that is characteristic of spoken languages. Progress in information and documentation technologies makes it possible to represent different types of variation, and to produce materials, which reflect local ways of speaking as alternatives. Modern dictionaries and grammars are based on substantial collections of oral usage and might include 'crowd sourcing', i.e. the gathering of information from large numbers of people through the Internet. With this focus on spoken natural conversation, linguistic diversity and variation are recognized and respected. In such projects, speakers are instrumental in carrying out this research as well as in the processing and analysis of the language data. 


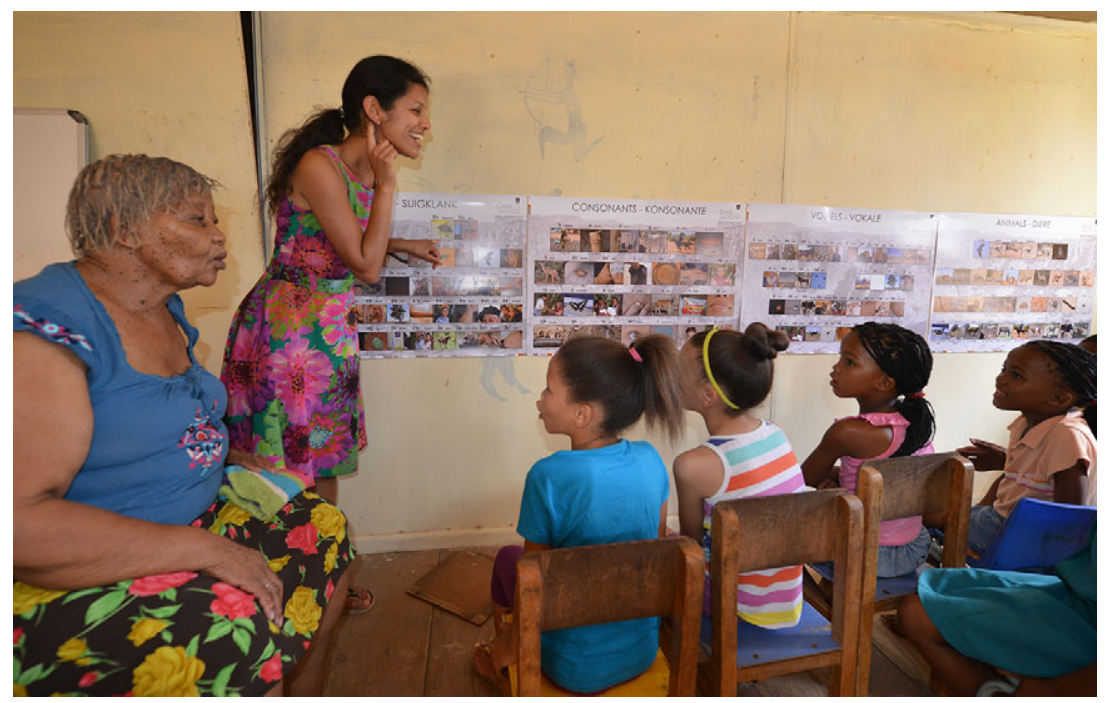

Figure 14.2 Katrina Esau and Sheena Shah introduce the newly developed Nluu alphabet charts. Photo by Matthias Brenzinger

\section{Ownership and Management of Orthographies}

Community orthographies can stimulate intense emotional reactions among communities, for example, related to who controls and has the authority over language standardization efforts, or even more fundamentally, who owns a language. Communities have different options to coordinate and manage language activities. Community language boards may manage the development and establishment of writing conventions. This, however, is often not a straightforward exercise due to intra-community disagreements about writing conventions that can arise. Communities are not monolithic and there might be disagreements about whether and how to write languages. For example, different generations may have different opinions on the use of digital technologies; while younger generations may favour the use of social media, online video, text messaging, podcasts and various other technologies, older generations may be opposed to this (but see Figure 14.3). Interventions through government policies, conflicting conventions of different religious traditions, etc., often add to the complexities of the task of establishing writing systems for oral languages. It is imperative, however, that language communities themselves head and direct these efforts to ensure that their own interests are respected. 


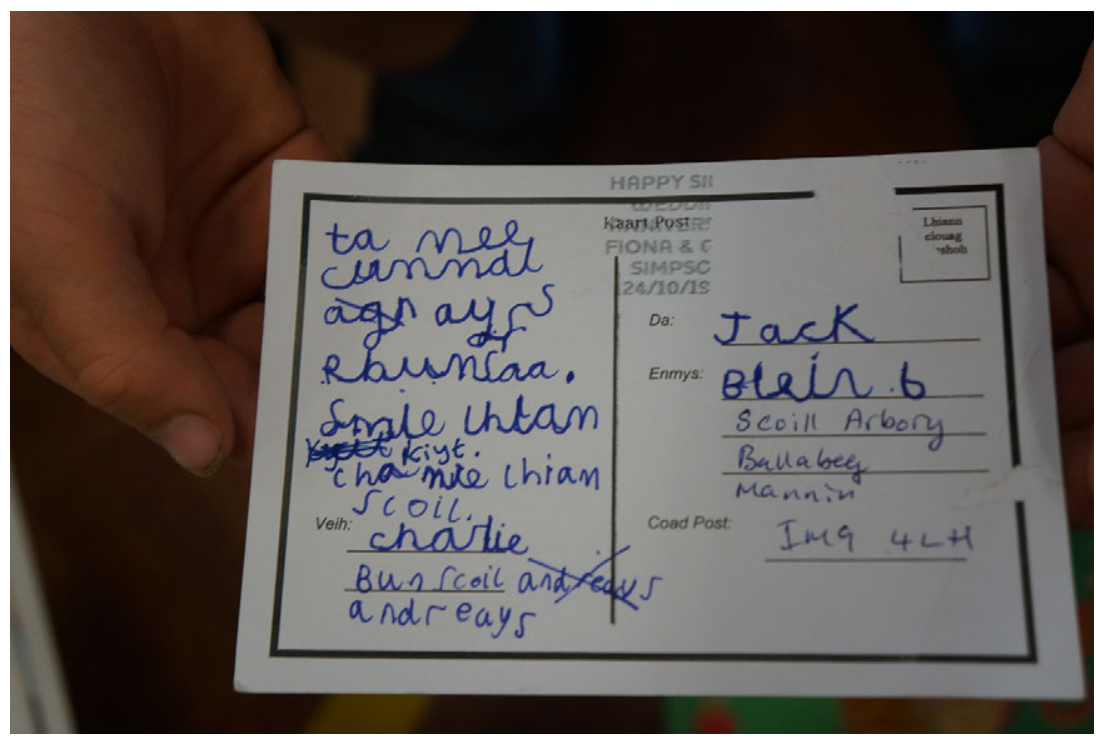

Figure 14.3 A postcard written by a young student of Manx. Photo by Justyna Olko

\section{Summary}

There is no single best way to establish literacy in previously unwritten languages of predominantly oral communities. Even though one can learn from the various previous and ongoing attempts to write languages, community settings and conditions differ substantially. The level of literacy among community members (also in languages other than their own), whether a closely related language is already written, or if national policies prescribe writing systems or alphabets, are among the core factors that need to be considered when developing community orthographies for previously unwritten languages.

The possible purposes for and the uses of written forms for oral languages are numerous. In most cases, the development and production of written teaching and learning materials are essential when intergenerational language transmission is interrupted and when languages are thus learned mainly in formal or informal teaching settings. Where archived recordings of past or living speakers exist, such as in Australia or Hawai'i, community members can also relearn and regain oral competence in dormant ancestral languages.

Introducing writing for oral languages often has a positive impact on the self-esteem of their speakers and contributes to the improvement of their well-being. Visualizing their languages in writing can be an important tool 


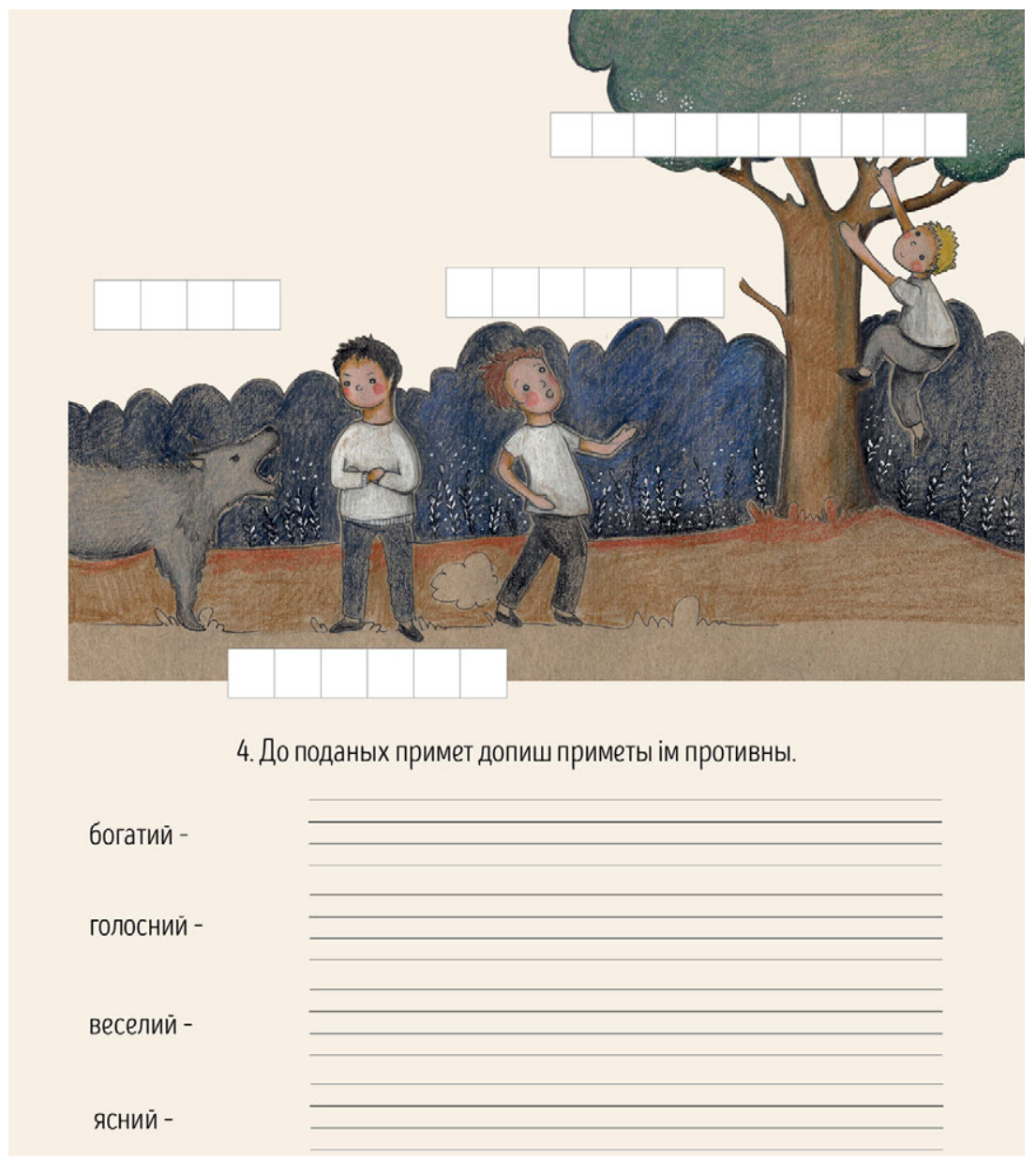

Figure 14.4 An exercise book for (writing) the Lemko language (Робочий зошыл до лемківского языка), Barbara Duć/Варвара Дуць, () Engaged Humanities Project, University of Warsaw

in the empowerment of marginalized communities. Furthermore, many rural communities in various parts of the world have very little or no access to electronic language resources (e.g. no electricity, no recording devices, no smartphones, etc.), making the use of audio or video clips in teaching efforts problematic. For that reason, in the foreseeable future, writing an oral language may still prove to be essential for the production of teaching materials, and literacy will remain the main tool for accessing knowledge and information (Figure 14.4). 
Most important for the development and establishment of writing for oral languages - besides communities being in control of all activities that aim at establishing community orthographies for their languages is that community members wish to have their languages written.

\section{FURTHER READING}

Cahill, M. and Karan, E. (2008). Factors in designing effective orthographies for unwritten languages. SIL Electronic Working Paper 2008-001. www.sil.org/resources/archives/7830.

Jones, M. and Mooney, D., eds. (2017). Creating Orthographies for Endangered Languages. Cambridge: Cambridge University Press.

Seifart, F. (2006). Orthography development. In J. Gippert, N. P. Himmelmann, and U. Mosel, eds., Essentials of Language Documentation (Trends in Linguistics. Studies and Monographs 178). Berlin: Mouton de Gruyter, pp. 275-99.

\subsection{Orthographies and Ideologies}

\section{Tomasz Wicherkiewicz}

Very often, language communities and activists want to make their language visible through developing a script, writing system, orthography, individual letters or type fonts. The choices involved in deciding the graphic layout make language ideologies tangible. Developing a written form (graphization) of a language (variety) not only involves the selection of an appropriate orthography, but also making decisions concerning cultural, religious, political and historical matters.

Ideological factors are therefore fundamental when considering how to write minority languages. However, it is always the community who should have the decisive voice when adopting script, writing system and orthography. Of course, there are often disagreements within a community on writing and/ or orthography.

Many minorities use writing to symbolically mark their territory, using public signs to mark the names of settlements, municipalities or other places within the area of a dominant language. Sometimes the languages used in the signs are perceived as rival or competing against each other - occasionally this also applies to rival orthographies for the same 'language' (e.g. Provençal/Occitan orthographies in southern France, or 'standard' vs. 'dialectal' forms, e.g. in Italian Lombardy, Piedmont or Veneto). Place names may be written in two or more languages or writing systems, and it is quite common for a name in one language to be removed, altered or painted over as a visible sign of ethno-linguistic conflict, an example being a letter $\mathbf{V}$ in an Anglicized place-name in Wales replaced by an $\mathbf{F}$. 


\section{Explanation of Terms}

A script is a set of graphic signs (graphemes) for writing languages, which contains information about the basic level of language to which its signs correspond: words, syllables or phonemes.

A writing system is the implementation of a script (or sometimes elements of more than one script) to form a complete system for writing a particular language variety; a writing system can be standardized by means of an orthography, i.e. norms for spelling, diacritics (e.g. accents etc.) and punctuation, which are often arranged and published as spelling rules and orthographic dictionaries. These norms may be explicit or implicit: implicit norms often allow a greater degree of variation than explicit orthographic norms.

Fonts or typefaces are graphical variants, which can be distinguished within a script.

Traditionally, a script or graphic layout has been ideologically related to culture, and even more often with religion. Many people spontaneously associate the Cyrillic script with the Christian Eastern Orthodoxy, Arabic with Islamic tradition, Hebrew with Judaism, Devanagari with Hinduism and Chinese characters with the East Asian cultural sphere. For a long time, the Latin script was linked to the Western European tradition and Western Christianity. In regions of Europe where Protestant and Catholic traditions rivaled each other, the visible factor used to differentiate them was a type font: protestant writings adopted $\mathfrak{B l a c k l e t t e r}$ or $\mathfrak{G o t h i c ~ s c r i p t , ~ w h i l e ~ C a t h o l i c ~ p u b l i c a t i o n s ~ u s e d ~ A n t i q u a ~ t y p e f a c e . ~}$

Throughout history, scripts have been designed specifically for individual languages - examples being the Georgian scripts ( Asomtavruli, Nuskhuri, and Mkhedruli, the Armenian Zujtiptidh ujpntpti / Hayereni aybuben for Armenian, the Korean 한글 / Hangul, or the syllabaries ひらがな/ Hiragana and カタカナ/ Katakana for Japanese. These and other 'national' scripts became carriers and symbols of various 'nation-state' ideologies in the nineteenth and twentieth centuries.

The same nation-state ideologies were also behind the adoption or imposition of dominant scripts as writing systems for minority languages (no matter whether they were linguistically related or not), e.g. in Georgia for Abkhazian, Ossetian, Svan, Megrelian, or in Japan for Ainu or Ryūkyūan.

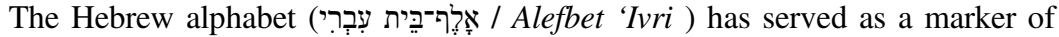
Jewishness, and as such has been applied to most of the Jewish languages spoken all over the world (Yiddish, Ladino, Judeo-Persian, and many others). The same alphabet was originally adopted by the Karaims, a Turkic people of Judaic religious tradition. In the nineteenth/twentieth centuries, the Karaim communities in Lithuania and Poland decided to switch from Hebrew to Latin script in order to visually mark their separation from Jewish ethnicity. Later, Karaims under Soviet rule had to adopt a Russian Cyrillic-based orthography. Even some Yiddish 
speakers in the same period thought about switching from the Hebrew script to the Polish Latin-based writing system. From a contemporary educational perspective, it might be easier to learn using the same script as the dominant education system, although it can also encourage faster language shift. The majority of world's languages have not been recorded in writing and there are fewer scripts and writing systems than language varieties in the world. Furthermore, many language communities have made changes to their orthographies or individual graphemes (e.g. Vietnamese and Turkish switching to Latin script).

Any language or language variety can be written with any writing system or script, although e.g. arguably syllabaries are more suitable for languages with Consonant+Vowel syllables. However, there are many factors involved in devising or adapting a writing system or orthography, and these must be considered in order for an orthography to be effective. The process is more complex than is commonly realized.

Here are some key factors to be taken into consideration when designing effective orthographies:

(1) Governmental, administrative and legal policies, obligations and restrictions, which must be considered when working on community-driven (bottom-up or grassroots) projects. For example, in Ghana all writing systems have to use the national orthographical conventions. ${ }^{2}$

(2) Cultural or religious traditions, e.g. ease of access to earlier written materials such as pre-Conquest Central American manuscripts, visual appearance (i.e. symbolic meaning of individual graphemes), the values attached to a script or typeface (e.g. the close relationship between Arabic script and Islam).

(3) Linguistic factors, including sound-grapheme or meaning-grapheme correspondence (according to the script type), or how to decide where word breaks come.

(4) Educational and social factors, including literacy issues and ease of learning, access to the learning of additional language.

(5) Sociolinguistic aspects - including language ideologies, attitudes, how to choose the 'standard' variety and its applicability to other varieties of the language in question.

(6) Need and importance of written language documentation for the community.

Inventing a script is one way that a community can try to create a distinct identity. Sometimes creating and developing a uniquely new script is the most accepted way to develop and promote social literacy within a language community. One such case is the well-documented Indigenous script of N'ko in West Africa. The N'ko 'social orthography' has successfully competed against other older writing systems that have been better propagated in the colonial and national literacy education programs. N'ko's popularity results from the script's

2 See M. Cahill, 'Non-linguistic factors in orthographies', in M. Cahill and K. Rice (eds.), Developing Orthographies for Unwritten Languages (Dallas: SIL International, 2014), pp. 9-25. 
strong linguistic and cultural relevance to the Mande communities and their Indigenous knowledge.

Some minority language communities prefer to use a special font (such as the contemporary Basque Harri / Vasca or the historical Gaelic script for the Celtic languages), or a unique, recognizable type style (e.g. mixed-case oblique Irish vs. capital lettered English on road signs in the Republic of Ireland). In such cases, the graphic features of the script became symbolically relevant, acting as distinctive markers of the linguistic landscape. On the other hand, some members of the community might object to such 'ethnic fonts' as markers of folklorization or archaization.

If a language community uses the same script as the surrounding dominant language(s), individual graphemes (e.g. particular letters in alphabets) or even individual diacritic signs, i.e. additional graphic marks of letters, might become ideological carriers and visible indices of identity. Examples of the latter include, e.g.

- the letters $\ddot{\mathbf{e}} \dot{\mathbf{e}} \dot{\mathbf{a}}$ are, respectively, considered the most Kashubian, most Lithuanian, and most Wymysiöeryś (all three are minority/regional languages in Poland);

- the letter q marks plurals in Võro (or Southern Estonian - an unrecognized regional language in Estonia), while Standard Estonian uses d for the same function;

- the letter $\overline{\mathbf{0}}$ is used in some orthographies of Latgalian (a regional language in Latvia), but was officially outlawed by the Latvian language authorities for not corresponding to the general Latvian graphic tradition;

- the letter $\mathbf{I}$ was used traditionally in Ukrainian orthography, but forbidden by the Soviet orthographic reforms in the 1930s, as 'too much Western and too little Soviet';

- the letters $\mathbf{q}, \mathbf{w}$ and $\mathbf{x}$ were forbidden by Turkish law since 1928, when Turkey changed its alphabet from an Arabic-based system to a Latin one. The change was intended to standardize Turkish spelling and improve literacy. However, the reform also had a political aim: assimilating Turkey's minorities, chiefly the Kurds. For many years, any Kurdish person whose name contained a Q, W or $\mathrm{X}$, for example, could not have those letters included on their official documents. In the 2000s, Kurdish language activists launched a 'Q-X-W' campaign, which led to the abolishment of the ban in 2013 .

\section{FURTHER READING}

Anderson, B. (1983). Imagined Communities. London: Verso.

Bielenberg, B. (1999). Indigenous language codification: Cultural effects. In J. Reyhner et al., eds., Revitalizing Indigenous Languages. Flagstaff, AZ: Northern Arizona University, pp. 103-12. http://jan.ucc.nau.edu/ jar/RIL_8.html.

Cahill, M. and Rice, K., eds. (2014). Developing Orthographies for Unwritten Languages. Dallas: SIL International; see especially the 'Introduction' and 'Orthography Wars' by Leanne Hinton. 
Sebba, M. (2007). Spelling and Society: The Culture and Politics of Orthography around the World. Cambridge: Cambridge University Press.

\subsection{Writing Your Language: The Case of Wymysiöeryś Tymoteusz, Król}

When I was ten I became aware of a big threat to my language, Wymysiöeryś, and so I wanted to protect it. The problem was, I did not know how to do it. Somebody told me that the more recordings and texts there are of a language the better. The first thing I did was to record my grandma and her friends speaking Wymysiöeryś. But I knew that my recordings should include more literary forms of the language. As a child I had no access to Biesik's poetry. Florian Biesik (1850-1926) is a Wymysiöeryś poet who spent most of his life in Trieste. I knew the local songs and oral poetry, but there were very few texts which I could read, as all of them were written in various orthographies.

I had the good fortune to meet Józef Gara fum Tołer, who was the only person publishing poems in Wymysiöeryś at that time. He taught me how to use his orthography and he checked my poems for me. Another person who helped me with my first poems was Ingeborg Matzner-Danek: she translated some poems from the Bielitz-Bialaer variant of German into Wymysiöeryś.

The goal of these first texts that I wrote was language documentation. Of course, this documentation was the work of an eleven-year-old child and it was not like the documentation carried out by professionals. The most important part of the work was the inclusion of a variety of themes and grammatical forms, but I was afraid of inventing new words. Inventing new words is always a political or ideological decision: should it be a word taken from a foreign language like Polish, German, English, or maybe a new word created by myself? Those texts from when I was child are now sometimes used as teaching materials, but they are mostly kept 'in the drawer'.

Then, there was a request for Wymysiöeryś texts from the local Dance Group 'Wilamowice': sometimes they needed a translation of a Polish song that they sung, sometimes I would tell them a poem or some greetings in rhyme for an important person and sometimes I would invent a new song for a special occasion. I often still do this.

Then I started writing some 'bigger' texts, including novels and poems. But I often heard people say: 'Your language is not really a language. We Poles have a large and varied literature with many poets, such as Mickiewicz etc.' I was angry about this, because the goal of these statements was to humiliate speakers of Wymysiöeryś. So I decided to change this and I wrote many poems and prose in different genres. When I was sixteen, one of the stories I wrote was called S'tawa fum Wilhelm ('The life of Wilhelm'). It recounted the genesis of Wymysoü-Wilamowice and was printed by the Association 'Wilamowianie'. However, for me the most important texts are those that I wrote for the Dance Group because they are the texts that are most 'alive': they are sung by the Dance Group as 'old Wymysiöeryś songs' and nobody remembers that I am the author. The Christmas carols I translated from Polish to Wymysiöeryś 
are sung alongside their Polish equivalents by children going from house to house at Christmas time. For me it is beautiful that my texts, of whose quality I was so anxious, are now a part of the Vilamovian oral poetry collection. I also find it beautiful that, for Vilamovians, I am equal with tens of authors whose names are not known anymore, but whose texts have been sung for hundreds of years.

The second piece of luck I have had is that my students started writing their own texts. I must say, when I was being taught by Inga-Müm and Jüza-Feter, I never dreamt about having my own pupils in the future. As I wrote above, I was previously afraid of inventing new words which could be used for new things that I wanted to include in teaching materials that I created. Now, after the two successes that I have written about, I feel authorized to do so.

\subsection{Indigenous Research, Methodology and Writing}

\section{John Sullivan}

The books and articles that have been written recently on the topic of Indigenous research and methodology have two things in common. First, they are written in dominant languages, such as English and Spanish, rather than in the Indigenous languages themselves. Second, they are largely theoretical; in other words, they talk about what Indigenous research and methodology should look like and what its political function should be, but they rarely actually do it. At the Instituto de docencia e investigación etnológica de Zacatecas (IDIEZ, see Capsule 8.5) we have been conducting curriculum development and research in the area of Nahuatl language and culture for the past seventeen years, and we have done it monolingually, in Nahuatl. We work on the premise that for research and methodology to be considered 'Indigenous', it should be performed from within the unique worldview and cognitive structures of each specific culture. And these can best be accessed, understood, developed and expressed through each culture's language. Here are four examples of how we perform research at IDIEZ.

Example 1: During the course of writing Tlahtolxitlauhcayotl, Chicontepec, Veracruz, our monolingual dictionary of Modern Huastecan Nahuatl, we created a tremendous amount of neologisms for grammatical terminology. But we never simply translate terminology from European languages, as is common with the Mexican bilingual school system. We always begin with a concept, discuss it collectively in Nahuatl, and when we understand what we want to express, we use the morphological resources of Nahuatl to create a term. For example, we took the verb tocaxtia 'to name something' and turned it into a gerund tlatocaxtiliztli 'the act of providing something with a name'. This is the neologism we use to express the concept of 'noun'. Nahuatl nouns have subjects; rather than a simple label, they constitute a process for providing a subject with a name.

Example 2: At a conference in Chihuahua in 2016, a panel of native speakers of different Uto-Aztecan languages gave talks in Spanish about colour terminology in their culture. During the question and answer session, I explained that Modern Huastecan Nahuatl, also a Uto-Aztecan language, doesn't employ the concept of colour; rather it uses ixnezcayotl 'something's surface appearance', which includes 
colours, but also such things as stripes, polka dots, stains, and certain types of visible textures. The panel participants responded that their languages worked in the same ways, but they had just uncritically assumed that the Western concept of colour was universal.

Example 3: Eduardo de la Cruz Cruz wrote his master's thesis in Nahuatl on the topic of corn, at the Universidad Autónoma de Zacatecas in 2016. When we were discussing how to organize his work, I suggested a typical Western model with chapters on land, planting methods, tools and deities, etc. But Eduardo responded that as an Indigenous person this didn't make sense to him at all. He proposed chapters on each one of the ceremonies that comprised the yearly agriculture cycle, with each chapter discussing the aspects of land, planting methods and tools, deities, etc., that it employed. He chose to focus on the interrelation of his topics, rather than to compartmentalize them.

During five hundred years of contact with Europe, Nahuas have never been purists: they have adopted foreign things that are useful and ignored those that are not. At IDIEZ we do not seek to discard all foreign ways of perception and principles of organization. Rather we conduct research to discover what in today's Nahuatl culture is native and what is of foreign origin, so that native speakers can make informed decisions about how they wish to generate and organize knowledge and how they write about their culture in their own language. 